\title{
EDITORIAL
}

\section{Device Therapy in Heart Failure}

The management of patients with heart failure incurs a substantial economic burden and hospitalization is responsible for more than $50 \%$ of this expense. ${ }^{1}$ There have been in-tensive efforts to develop device-based therapies aimed at improving cardiac reserve and optimizing pump function to meet metabolic requirements. Currently available devices for heart failure are cardiac resynchronization therapy (CRT) and left ventricular assist device (LVAD). Resynchronization therapy (CRT) is available with two different function; CRT-Pacemakers (CRT-P) and CRT-Implantable cardioverter defibrillator (CRT-D). The clinical effects of long-term CRT have been evaluated in a large number of randomized multi-centre trials with crossover or parallel treatment assignment, ${ }^{2-8}$ The usual study enrolment criteria were: NYHA function class III or IV despite optimal pharmacological treatment, LVEF $\leq 35 \%$, sinus rhythm (SR), left ventricular (LV) dilatation but with varying definitions, and QRS duration e”120/ e” 130 ms. On average, NYHA function class decreased by $0.5-0.8$ points, the 6 min walk distance increased by $20 \%$, and peak oxygen consumption increased by 10-15\%. The functional benefits and quality of life improvements were sustained. ${ }^{9,10}$ Apart from this CARE-HF and COMPANION trials showed considerable improvement in morbidity and mortality (unplanned hospitalizations for major cardiovascular events by 39\% and all-cause mortality, relative risk reduction: 36\% ), ${ }^{11,12}$ There is $15 \%$ absolute reduction in LV end-diastolic diameter and an up to 6\% increase in LVEF following CRT. ${ }^{13,14}$ In ambulatory patients in NYHA IV, CRT showed considerable morbidity benefit. A baseline typical left bundle branch block (LBBB) pattern predicted a favorable outcome, whereas prolonged PR interval and right bundle branch block (RBBB) were the only predictors of nonfavorable outcome. ${ }^{14}$

The role played by CRT in patients presenting with no or only mild manifestations of HF, a depressed LVEF and a wide QRS complex, in other words the patients were in NYHA class I and II. It was evaluated in MIRACLE ICD II, $^{6}$ MADIT CRT $^{15}$ and REVERSE ${ }^{16}$ trials. All these trials demonstrated reduced morbidity. Improvement was primarily seen in patients with QRS $\geq 150 \mathrm{~ms}$ and/or typical LBBB. Women with LBBB demonstrated a particularly favorable response. In MADIT-CRT the extent of reverse remodeling was concordant with and predictive of improvement in clinical outcomes.

At present most of the randomized studies of CRT has been almost exclusively restricted to patients in sinus rhythm. In Europe approximately one-fifth of patients receiving CRTs have permanent atrial fibrillation (AF). This group is not addressed in guidelines and only small number of randomized trials was conducted in recent past. It is seen in these patients if AV node ablation is done after CRT implantation. ${ }^{17}$ These patients are benefited most.

In patients with conventional indications for pacemaker implantation and LV dysfunction, chronic RV pacing will increase the dyssynchrony. Initiation and up titration of $\beta$-blocker treatment, indicated in patients with symptomatic heart failure, may reduce heart rate and increase pacemaker dependency. Patients with a CRT will better tolerate increased pacing time. This may permit initiation of $\beta$ blocking treatment or dosage increase in those patients who are already on therapy. ${ }^{18-20}$ This will benefit clearly this sub group.

Patients with end-stage heart failure have a poor quality of life, a very high mortality rate, and are potential candidates for implantation of a left ventricular assist device (LVAD). Although cardiac transplantation is associated with high 1- and 10-year survival rates, organ supply is limited. The technical improvements and proven success of implantable LVADs have made it a reasonable treatment option in these patients, either as a bridge to cardiac transplantation or as destination therapy. Patient selection for LVAD is crucial. These patients are mostly on continuous inotropic support. Patients with severe renal, pulmonary, or hepatic dysfunction as well as patients with active infection or cardiogenic shock should not be considered as candidates. ${ }^{21}$ There are two types of LVAD; one with continuous flow and other with pulsatile flow. Most of these patients are in NYHA function class IIIB/IV with an LVEF of $\leq 25 \%$. The available evidence suggests that a continuous flow device is superior to a pulsatile flow device. ${ }^{22}$

Lastly, we would like to say that patient selection is moving beyond the QRS. There are several expanding indications into the realm of patients who are mildly symptomatic, and 
who have a narrow QRS. In our country number of patients with heart failure is increasing day by day due to the advancement in the therapeutic options for acute cardiac emergencies e.g. acute myocardial infarction. This group of patients is suffering a lot due to repeated hospitalization and poor quality of life. They will be benefited most if these devices are used for them. However physicians should understand that choosing longevity with potential tradeoffs in device related complications and quality of life is a personal decision that must be individually tailored to patient preference. It is very important that we should be honest with the data, so that we can be honest with our patients.

\section{Prof. Md.Abu Siddique ${ }^{1}$, Dr. Mohammad Salman ${ }^{2}$}

${ }^{1}$ Chairman, Department of Cardiology, Bangabandhu Sheikh Mujib Medical University (BSMMU), Dhaka, ${ }^{2}$ Assistant Professor of Cardiology, Anwer Khan Modern Medical College, Dhanmondi, Dhaka.

\section{References}

1. Stewart S, Jenkins A, Buchan S, McGuire A, Capewell S, McMurray JJ. The current cost of heart failure to the National Health Service in the UK. Eur J Heart Fail 2002;4:361-71.

2. Abraham WT, Fisher WG, Smith AL, Delurgio DB, Leon AR, Loh E, Kocovic DZ, Packer M, Clavell AL, Hayes DL, Ellestad M, Trupp RJ, Underwood J, Pickering F, Truex C, McAtee P, Messenger J. Cardiac resynchronization in chronic heart failure. N Engl J Med 2002;346:1845-53.

3. Auricchio A, Stellbrink C, Sack S, Block M, Vogt J, Bakker P, Huth C, Schondube F, Wolfhard U, Bocker D, Krahnefeld O, Kirkels H. Long-term clinical effect of hemodynamically optimized cardiac resynchronization therapy in patients with heart failure and ventricular conduction delay. J Am Coll Cardiol 2002;39: 2026-33.

4. Higgins SL, Hummel JD, Niazi IK, Giudici MC, Worley SJ, Saxon LA, Boehmer JP, Higginbotham MB, De Marco T, Foster E, Yong PG. Cardiac resynchronization therapy for the treatment of heart failure in patients with intraventricular conduction delay and malignant ventricular tachyarrhythmias. J Am Coll Cardiol 2003;42: 1454-59.

5. Young JB, Abraham WT, Smith AL, Leon AR, Lieberman R, Wilkoff B, Canby RC,Schroeder JS, Liem LB, Hall S, Wheelan K. Combined cardiac resynchronization and implantable cardioversion defibrillation in advanced chronic heart failure: the MIRACLE ICD trial. JAMA 2003;289:2685-94.

6. Abraham WT, Young JB, Leon AR, Adler S, Bank AJ, Hall SA, Lieberman R, Liem LB, O’Connell JB, Schroeder JS, Wheelan KR. Effects of cardiac resynchronization on disease progression in patients with left ventricular systolic dysfunction, an indication for an implantable cardioverterdefibrillator, and mildly symptomatic chronic heart failure. Circulation 2004;110:2864-68.

7. Bristow MR, Saxon LA, Boehmer J, Krueger S, Kass DA, De Marco T, Carson P, DiCarlo L, DeMets D, White BG, DeVries DW, Feldman AM. Cardiac-resynchronization therapy with or without an implantable defibrillator in advanced chronic heart failure. N Engl J Med 2004;350:2140-50.

8. Cleland JG, Daubert JC, Erdmann E, Freemantle N, Gras D, Kappenberger L, Tavazzi L. The effect of cardiac resynchronization on morbidity and mortality in heart failure. N Engl J Med 2005;352:1539-49.

9. Linde C, Leclercq C, Rex S, Garrigue S, Lavergne T, Cazeau S, McKenna W, Fitzgerald M, Deharo JC, Alonso C, Walker S, Braunschweig F, Bailleul C, Daubert JC. Long-term benefits of biventricular pacing in congestive heart failure: results from the MUltisite STimulation in cardiomyopathy (MUSTIC) study. J Am Coll Cardiol 2002;40:111-18.

10. Cleland JG, Daubert JC, Erdmann E, Freemantle N, Gras D, Kappenberger L, Tavazzi L. Longer-term effects of cardiac resynchronization therapy on mortality in heart failure [the CArdiac REsynchronization-Heart Failure (CARE-HF) trial extension phase]. Eur Heart J 2006;27:1928-32.

11. Cleland JG, Daubert JC, Erdmann E, Freemantle N, Gras D, Kappenberger L, Tavazzi L. The effect of cardiac resynchronization on morbidity and mortality in heart failure. N Engl J Med 2005;352:1539-49.

12. Cleland JG, Daubert JC, Erdmann E, Freemantle N, Gras D, Kappenberger L, Tavazzi L. Longer-term effects of cardiac resynchronization therapy on mortality in heart failure [the CArdiac REsynchronization-Heart Failure (CARE-HF) trial extension phase]. Eur Heart J 2006;27:1928-32.

13. Linde C, Leclercq C, Rex S, Garrigue S, Lavergne T, Cazeau S, McKenna W, Fitzgerald M, Deharo JC, Alonso C, Walker S, Braunschweig F, Bailleul C, Daubert JC. Long-term benefits of biventricular pacing in congestive heart failure: results from the MUltisite STimulation in cardiomyopathy (MUSTIC) study. J Am Coll Cardiol 2002;40:111-18.

14. Gervais R, Leclercq C, Shankar A, Jacobs S, Eiskjaer H, Johannessen A, Freemantle N, Cleland JG, Tavazzi L, Daubert C. Surface electrocardiogram to predict outcome in candidates for cardiac resynchronization therapy: a sub analysis of the CARE-HF trial. Eur J Heart Fail 2009;11:699-705.

15. Moss AJ, Hall WJ, Cannom DS, Klein H, Brown MW, Daubert JP, Estes NA 3rd,Foster E, Greenberg H, Higgins SL, Pfeffer MA, Solomon SD, Wilber D, Zareba W. Cardiacresynchronization therapy for the prevention of heart-failure events. N Engl J Med 2009;361:1329-38.

16. Linde C, Abraham WT, Gold MR, St John Sutton M, Ghio S, Daubert C. Randomized trial of cardiac resynchronization in mildly symptomatic heart failure patients and in asymptomatic patients with left ventricular dysfunction and previous heart failure symptoms. J Am Coll Cardiol 2008;52:1834-43. 
17. Ferreira AM, Adragao P, Cavaco DM, Candeias R, Morgado FB, Santos KR, Santos E, Silva JA. Benefit of cardiac resynchronization therapy in atrial fibrillation patients vs. patients in sinus rhythm: the role of atrioventricular junction ablation. Europace 2008;10:809-15.

18. Vatankulu MA, Goktekin O, Kaya MG, Ayhan S, Kucukdurmaz Z, Sutton R, Henein M. Effect of long-term resynchronization therapy on left ventricular remodeling in pacemaker patients upgraded to biventricular devices. Am J Cardiol 2009;103:1280-84.

19. Paparella G, Sciarra L, Capulzini L, Francesconi A, De Asmundis C, Sarkozy A, Cazzin R, Brugada P. Long-term effects of upgrading to biventricular pacing: differences with cardiac resynchronization therapy as primary indication. Pacing Clin Electrophysiol 2010;33:841-49.

20. van Geldorp IE, Vernooy K, Delhaas T, Prins MH, Crijns HJ, Prinzen FW, Dijkman B. Beneficial effects of biventricular pacing in chronically right ventricular paced patients with mild cardiomyopathy. Europace 2010;12:223-29.

21. Lund LH, Matthews J, Aaronson K. Patient selection for left ventricular assist devices. Eur J Heart Fail 2010;12:434-43.

22. Slaughter MS, Rogers JG, Milano CA, Russell SD, Conte JV, Feldman D, Sun B, Tatooles AJ, Delgado RM 3rd, Long JW, Wozniak TC, Ghumman W, Farrar DJ, Frazier OH. Advanced heart failure treated with continuous-flow left ventricular assist device. N Engl J Med 2009; 361: 2241-51. 